most important contributions to chemistry in its applications to explosives and to metallurgy. Foremost among these are his researches into the preparation and uses of gun-cotton as an explosive, which were summarised in a paper printed in the Philosophical Transactions of 1866 and in the Bakerian lecture which appeared in the Philosophical 7ransactions of the following year. Guncotton was already known at that time, but it was generally regarded, at any rate in this country, as a dangerous and probably inefficient substitute for gunpowder. Abel showed, as the result of a long series of carefully chosen and elaborate experiments, how the material may be safely prepared of constant composition, how it should be stored, and also indicated its value as an explosive agent. These papers are eminently characteristic of the practical bent of Abel's mind. Though interested in the progress of pure science, his own inclinations were in the direciion of its applications. With the exception of a few of his early papers, written whilst he was Hofmann's assistant, nearly all his contributions have been to the applications of chemical science, and have been made with the express purpose of solving practical problems.

In connection with his other work on explosives, the researches, carried on in conjunction with Sir Andrew Noble, on the chemical changes resulting from firing gunpowder under various conditions and those on the detonation of explosives may be specially mentioned. In I 888, Abel was appointed chairman of the Government Committee on Explosives, and as a result of a series of experiments conducted under its auspices, the smokeless explosive known as "cordite," containing both gun. cotton and nitroglycerine, was patented by Abel and Dewar, and became the standard explosive of this country.

The influence of composition on the properties of steel and its analysis and the testing of petroleum also engaged his attention. The apparatus known by his name which he devised in connection with the Petroleum Acts of 1868 and 1879 for determining the temperature at which petroleum gives off inflammable vapour is still in general use, and he became a recognised authority on petroleum and its employment as an illuminating agent.

As a member of the Royal Commission on Accidents in Mines, he investigated the cause of the explosion at the Seaham Colliery in $188 \mathrm{I}$, and its connection with the presence of coal dust in the air.

No account of Abel's career can be complete without some reference to what he regarded as the most important work of his life. From the first he took a leading and responsible part in the movement which led to the foundation of the Imperial Institute. He was the secretary to the first organising committee, and in a lecture delivered at the Royal Institution in 1887 he gave an account of the work which the Institute proposed to accomplish. It is noteworthy that the need for further provision in this country for scientific research in connection with art and manufactures was one of the principal points in this lecture. On the opening of the Imperial Institute in 1893, Abel was appointed its secretary and director, a post which he held, latterly in an honorary capacity, until his death. Although already far advanced in life, Abel threw himself with great courage and determination into the difficult task of organising the operations of the Institute, and continued to do so even in the face of steadily declining health. In relation to the history of the Imperial Institute, it need only be noticed here that in 1894 a laboratory was equipped on a small scale for the chemical examination of Indian and Colonial products. In 1896 , a scientific and technical department, including extensive laboratories, was established with Prof. Dunstan as director, but the necessary funds were supplied by the Royal Commissioners of the 1851 exhibition, all the available funds of the Institute having been allocated to other purposes. Although it was Abel's intention to No. 1716 , vor. 66] retire from official connection with the Imperial Institute on its transfer to the Board of Trade at the end of the present year, he characteristically expressed his intention of continuing to take an active part in its proceedings as a member of the advisory committee.

Abel was an influential member of many scientific societies. He was elected a Fellow of the Royal Society in 1860, and was awarded a Royal medal in 1887 for his researches on explosives. He became at an early age a Fellow of the Chemical Society, and filled several offices in the Society, in which he was always deeply interested; at the time of his death he was one of the oldest of its past presidents. Abel took a leading part in the foundation of the Institute of Chemistry, of the Society of Chemical Industry and of the Institution of Electrical Engineers, of all of which he became president. He was also president of the British Association in 1890 and of the Iron and Steel Institute in $1891 . \mathrm{He}$ had filled the offices of vice-president and chairman of the council of the Society of Arts, which awarded him the Albert medal in I884. Abel took an important part in the foundation of the City and Guilds of London Institute, and was at the time of his death chairman of its executive committee. He was an influential member of the court of the Goldsmiths' Company, of which he became prime warden in 1895. Abel's distinctions were numerous and varied. He was a D.C.L. of Oxford and a D.Sc. of Cambridge. He was made a C.B. in 1877 and was knighted six years later. The K.C.B. was conferred in 1891 , and he was created a baronet on the occasion of the opening of the Imperial Institute in 1893 . The last honour, that of the G.C.V.O., was conferred by the King soon after his accession, in recognition of Abel's personal services to the Royal Family.

Highly endowed with a practical mind, great common sense and a prodigious power of work, Abel was invaluable as a member of committees. His large experience in drafting official papers made him an excellent critic, and it may be safely asserted that few of the many documents submitted to him, by the institutions he was connected with, left his hands without substantial improvement As tine went on, routine work became a confirmed habit and the idea of a holiday positively repugnant to him, so much so that he found himself unable at the last to take rest and change, the necessity for which his friends and medical advisers so repeatedly urged on him.

W. R. D.

\section{AN INSTRUMENT FOR AIMING GUNS UNDER COVER.}

THE advantage of cover in military operations has been shown over and over again during the recent war in South Africa. But even when cover is available, the head of the soldier is exposed, while in the act of aiming, to the fire of an enemy. By means of the hyposcope the marksman is able to aim with considerable accuracy, while protected by a cover of earthwork or stones. Apparatus for sighting ordnance by means of mirrors has been employed by the war departments of several nations. ${ }^{1}$ But the inventor of the hyposcope, Mr. W. Loulten, has dealt with the problem of furnishing any existing rifle with a system of mirrors, whereby the act of aiming may be performed from a point several inches below the triggerguard. The hyposcope is shown in Fig. I attarhed to the service rifle, which is placed in position over the edge of a rough mass of stones used as cover. The marksman aims the rifle by looking into the mirror at the lower end of the vertical tube, his head being protected by cover. In this form of instrument, four mirrors are employed ; on looking into the instrument, the sights of the rifle are

$$
1 \text { "Treatise on Serrice Ordnance." (I on'on, r393). }
$$


seen nearly as clearly as under ordinary conditions, the system of mirrors merely translating the line of sight along the rifle, parallel to itself, to the distance of about eight or nine inches below the axis of the barrel of the rifle.

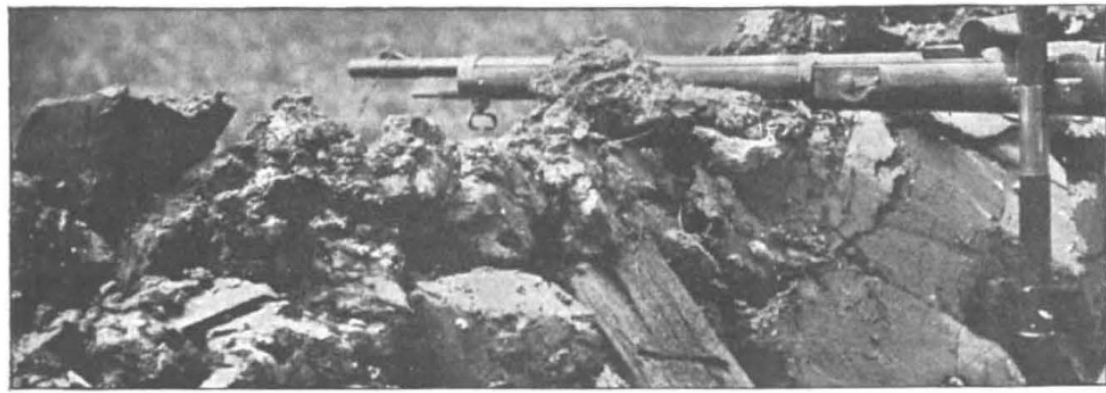

FIG. I.

In another form of hyposcope, used to sight a Maxim gun, Fig. 2, two mirrors only are employed to translate the line of sight downwards, and but little light is lost. The tube which carries the mirrors is graduated, and the correct elevation is obtained by means of two easily made movements of the apparatus.

The National Rifle Association, recognising the importance of shooting while protected by cover, awarded prizes at the Bisley meeting this year for shooting with the hyposcope sighting. The range was 200 yards, the bullseye seven inches; each man of the thirteen who shot had seven shots. The highest possible score was 35 per man, and the average score per man was 32.15 . The apparatus and the method of holding the rifle were new to nearly everyone who shot. In actual warfare, an enemy may approach a trench or cover from any direc-

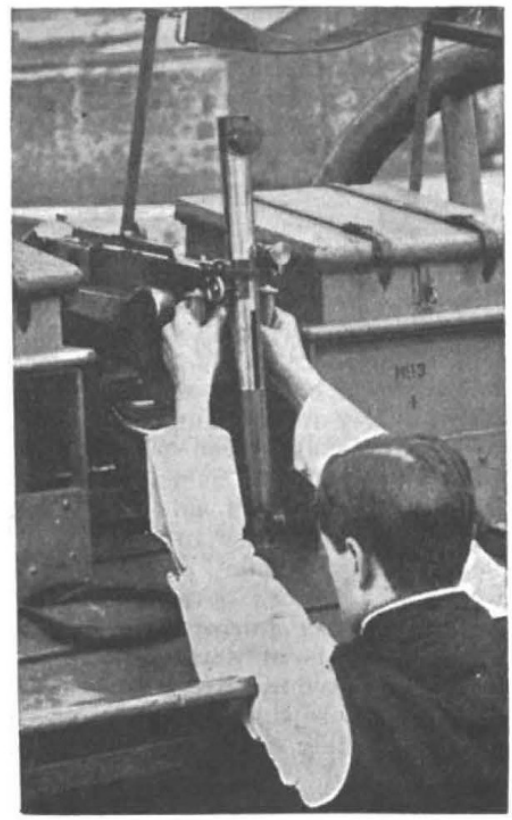

FIG. 2.

tion, and his approach must be seen, before the rifle is brought to bear on him. Probably the observation of the movements of the enemy might be found approximately by using a separate hyposcope, not attached to a No. I 7 I6, vOL. 66$]$ rifle in the usual way, so as to bring into view each portion of the foreground in succession. Such an instrument would only require two mirrors, and would enable an outlook to be kept with a minimum of danger to the observer. The instruments are strongly made, and with reasonable care they should efficiently answer their purpose.

THE BRITISH ASSOCIATION AT BELFAST.

$\mathrm{I}$ point of numbers, the 1 meeting of the British Association at Belfast has not been a very large one, but it has certainly been a decided success and has been full of interest. About sixteen hundred members and associates have attended, and in addition many people have been present at the meetings who have not registered their names. The local committee has facilitated the work of the secretaries in every possible way, and the excursions have been a means of pleasure and profit to all who have been able to take advantage of them. No meetings were held on Saturday, so that members should be free to avail themselves of the opportunity of taking part in the interesting excursions arranged for that day.

At the first meeting of the General Committee, the report of the Council was read. Reference to the severe loss the Association has sustained by the death of Mr. Griffith, the late assistant general secretary, was made in the first paragraph of the report, and it was announced that Dr. J. G. Garson had been nominated to succeed him in this important office. Sir William Roberts-Austen, K.C.B., having informed the Council that he did not intend to offer himself for re-election as general secretary, Major P. A. MacMahon, F.R.S., was appointed as his successor, and Prof. D. J. Cunningham, F.R.S., was elected to fill the vacancy thus caused among the members of the Council. In addition to Prof. Cunningham, the following members have been elected on the Council, the new names in the list being in italics:-Sir $W$. Abney, K.C.B., F.R.S. ; Prof. H. E. Armstrong, F.R.S. ; Dr. J. Bonar; Prof. F. O. Bower, F.R.S. ; Prof. H. L. Callendar, F.R S. ; Captain E. W. Creak, R.N., F.R.S. ; Major L. Darwin; the Hon. Sir C. W. Fremantle, K.C.B. ; Prof. F. Gotch, F.R.S. ; Prof. A. C. Haddon, F.R.S.; Prof. W. D. Halliburton, F.R.S. ; Mr. C. Hawksley; Prof. G. B. Howes, F.R.S. ; Dr. J. Scott Keltie ; Sir Oliver Lodge, F.R.S. : Prof. A. Macalister ; Prof. W. H. Perkin, F.R.S. ; Prof. John Perry, F.R.S.; Mr. L. L. Price ; Mr. A. C. Seward, F.R.S. ; Prof. W. J. Sollas, F.R.S. ; Prof. W. A. Tilden, F.R.S. ; Prof. W. W. Watts; Sir John Wolfe-Barry, K.C.B., F.R.S. Profs. H. Elster and J. Geitel have been elected corresponding members of the Association.

At the second meeting of the General Committee, Sir Norman Lockyer, K.C.B., F.R.S., was elected president of the Association next year. The meeting will be held at Southport, and will commence on September 9, 1903 . It was resolved to hold the meeting of 1904 at Cambridge, and in all probability the meeting of the following year will be held at Cape Town. The invitation to visit South Africa has been backed up by the promise of substantial pecuniary support, so that a large and representative number of members of the Association may be enabled to accept it.

The following grants of money for scientific purposes were recommended by the General Committee at the meeting on Monday:- 